\title{
“¡Hey! Un patacón ahí” Movilización de significados y construcción de identidades del barrio Getsemaní en Bizarre Foods ${ }^{1}$
}

\author{
“¡Hey! Un patacón ahí” Mobilization of meanings and construction of \\ identities in the Getsemaní neighborhood in Bizarre Foods
}

\author{
Julio Morales Fonseca ${ }^{2}$
}

\begin{abstract}
Resumen
Este ensayo busca establecer el modo como el programa de TV estadounidense Bizarre Foods Americas construye identidades y significaciones acerca del barrio Getsemaní (Cartagena de Indias, Colombia) en la interacción entre un 'cocinero aventurero' de habla inglesa y la gente local del barrio, mediante recursos multimodales. Para la descripción e interpretación de los datos acudimos, por un lado, a la etnografía virtual (Domínguez, et.al., 2007; Pauwels, 2012) y, por otro, a conceptos relacionados con el lenguaje y la globalización para explicar la construcción de identidades (Blommaert, 2010; Pietikäinen, 2018; Menezes de Souza, 2019; Stroud, 2017). Los resultados muestran que a través de un diverso repertorio de recursos semióticos utilizados durante el programa, se establecen distintos elementos identitarios locales así como la perpetuación y legitimización de fenómenos sociales adversos para la población local referidos a relaciones sociales desiguales de poder y discursos colonialistas.
\end{abstract}

Palabras clave: identidades, recursos multimodales, semiótica, sur global, discursos colonialistas.

\begin{abstract}
This essay seeks to establish the way in which the American TV show Bizarre Foods Americas builds up identities and meanings about the Getsemaní neighborhood (Cartagena de Indias, Colombia), during the interaction between an English-speaking 'adventurous cook' and the local people of the neighborhood, through multimodal resources. To describe and interpret the data we resort, on one hand, to virtual ethnography (Domínguez, et.al., 2007; Pauwels, 2012) and, on the other, to concepts related to language and globalization to explain the construction of identities (Blommaert, 2010; Pietikäinen, 2018; Menezes de Souza, 2019; Stroud, 2017). The results show that through a diverse repertoire of semiotic resources used during the program, different local identity traits are established. Results also evidence the perpetuation and legitimization of adverse social phenomena for the local population referred to unequal social relations of power and colonialist discourses.
\end{abstract}

Key words: identities, multimodal resources, semiotics, global south, colonialist discourses.

\footnotetext{
${ }^{1}$ El artículo hace parte del proyecto de investigación "Sabores y saberes en el Caribe colombiano" avalado por la Universidad de Cartagena, Colombia. También, es resultado de un ejercicio de investigación del seminario doctoral The Dynamics of Multilingualism:Dislocations de la Universidad de Estocolmo, Suecia, como parte de los cursos formativos del doctorado en Antropología de la Universidad Autónoma de Madrid, España.

${ }^{2}$ Doctorando en antropología Universidad Autónoma de Madrid, España. Correo: julio.morales@estudiante.uam.es. ORCID ID: https://orcid.org/0000-0001-9861-6564
}

Recibido: 31.08.2021 Aceptado: 10.10.2021 
“¡Hey! Un patacón ahí” Movilización de significados y construcción de identidades del barrio Getsemaní en Bizarre Foods

Julio Morales Fonseca

\section{Introducción}

En el contexto globalizado actual, las comidas callejeras se perfilan cada vez más como un rasgo identitario importante de una ciudad. En Nueva York, por ejemplo, disfrutar de un perro caliente o hot dog en el Central Park o en alguno de los paseos que bordean el río Hudson es un ritual necesario para quienes visitan la ciudad. En Lisboa y otras ciudades de Portugal es común encontrarse con humaredas en las esquinas de las calles donde se venden las populares castanhas assadas. En muchas ciudades asiáticas un sólo puesto callejero puede convocar a cientos de comensales que disfrutan de su comida sin importarles las presumidas desventajas o incomodidades asociadas a estos negocios: estar a la intemperie, de pie, sin mesa ni cubiertos, con muchas personas alrededor, etc. En España, en algunas plazas y parques, especialmente en ciudades turísticas, se pasean vendedores ambulantes de cerveza, conocidos popularmente como "pakis" o "lateros", quienes surten a los jóvenes que realizan sus típicas reuniones, conocidas en España como botellones, al aire libre para departir y beber.

En el caso de Colombia, el fenómeno de los puestos callejeros ha instituido un mercado propio basado en la informalidad dirigido a una clientela que busca saciar el hambre de manera rápida y barata; uno de esos mercados lo constituyen los puestos de comidas callejeras ubicados en la plaza de la Trinidad del barrio Getsemaní, en Cartagena de Indias. A diferencia de los Food trucks, (vehículos móviles en donde se comercializan las comidas) los cuales deben contar con todos los permisos sanitarios y de venta de alimentos tal y como lo haría un restaurante regular, los puestos de la plaza de la Trinidad se caracterizan por una falta total o parcial de permisos adecuados de funcionamiento. Esto los ubica en el campo de la informalidad laboral lo que, a su vez, los extrae de la superestructura del pago de impuestos y el control estatal.

Este tipo de eventos relacionados con las comidas callejeras ha originado un fenómeno mediático como el de la serie de TV estadounidense Bizarre Foods Americas, la cual registra las visitas del chef estadounidense Andrew Zimmern a distintos contextos culinarios del mundo. El chef se centra en las cocinas tradicionales locales de los lugares que visita y que popularmente se perciben como repugnantes, exóticas o extrañas.

Bizarre Foods ha sido objeto de estudios previos; por ejemplo, Kelly (2014) identifica a estos chefs como personajes de aventuras culinarias cuya dinámica representacional y retórica contribuye a "realzar el privilegio de los blancos". Señala el autor que Zimmern, por ejemplo, al comer todo tipo de comidas consideradas exóticas, amanguala la "crisis de identidad blanca" al asimilar lo exótico como parte del repertorio privilegiado de los blancos. A su vez, consumir del repertorio culinario radicalmente distinto de la Otredad contribuye a exaltar la "fama de occidente en cuanto a tolerancia y apreciación cultural, que trasciende la desigualdad de poderes globales y valida la superioridad de los valores democráticos Occidentales" (p.4). Finalmente, afirma Kelly, Bizarre Foods refuerza las diferencias entre "Nosotros y los Otros"; permitiendo que los "otros" existan siempre y cuando agraden al paladar de occidente. Por otra parte, Téwodros (2019) analiza episodios de Bizarre Foods en África y concluye acerca de sus modos de establecer la otredad: (1) 
“¡Hey! Un patacón ahí” Movilización de significados y construcción de identidades del barrio Getsemaní en Bizarre Foods

Julio Morales Fonseca

mediada por lo exótico como estereotipo en sus expresiones culturales y sus costumbres alimentarias; (2) presentada a través del espectáculo de la pobreza por lo que esas costumbres alimentarias no tienen ningún valor cultural pues solo sirven al sustento diario; y (3) mediada por el primitivismo, en contraste con el modernismo de occidente.

Lo que se observa en estos y otros estudios es que la mirada de Zimmern constituye, de hecho, una recontextualización de la "realidad buscada" o de las prácticas sociales "buscadas": en la primera mirada (la del chef) ocurrió "una relación psicológica de poder, en la que el observador es superior al objeto que observa" (Schroeder, 1998, p. 208). Pero, también, en esa mirada y en la del analista del video "Lo que se observa (...) se relaciona con la identidad de quien mira y el objeto observado" (Schroeder, 1998, p. 208).

Ahora bien, uno de los episodios de la serie Bizarre foods transcurrió en Cartagena de Indias, ciudad ubicada al norte de Colombia junto al mar Caribe, en el año 2015; este constituye nuestro objeto de investigación; de él, retomamos como dato para este ensayo el subapartado que transcurre en la plaza de la Trinidad del barrio Getsemaní, el cual tiene una duración de tres minutos y medio. El propósito de la investigación fue el de establecer el modo como el programa Bizarre Foods construye identidades y moviliza significados acerca del barrio Getsemaní (y de la ciudad de Cartagena), en la interacción entre el 'cocinero aventurero' de habla inglesa y la gente local del barrio, mediante recursos multimodales.

\section{La plaza de la Trinidad y el barrio de Getsemaní}

Fue en la plaza de la Santísima Trinidad donde, a mediados de 1810, se dio la organización y levantamiento popular conocido en la historia como Movimiento de los lanceros de Getsemaní, que apoyaron la insurrección criolla contra el gobierno real de Cartagena de Indias. Esta insurrección sentaría las bases para la posterior Declaración de Independencia de Cartagena del Imperio español, en noviembre de 1811.

El emplazamiento del barrio Getsemaní, lugar donde se encuentra la plaza, al igual que el resto de la antigua ciudad colonial de Cartagena, ocurrió en el antiguo territorio ocupado por el cacique Kalamarí, alto dirigente de la sociedad indígena de origen Karibe que habitaba la región (Anglería, 1944; Dussan, 1954; Reichel-Dolmatoff, 1955, 1986, 1990; Pineda, 1988 y Bernal \& Orjuela, 1992). La iglesia de la Trinidad fue erigida en este sitio por pedido expreso del obispo de la época al rey. Sin embargo, la razón incipiente puede responder a una estrategia colonial española de dominación política y simbólica sobre la población autóctona, al instaurar sus propios templos en lugares densamente poblados por antiguas sociedades indígenas; de hecho, el barrio de Getsemaní se ideó como un arrabal de la época colonial. Ubicado a las afueras de la Ciudad amurallada, era el lugar que habitaban los negros e indígenas esclavizados (Lemaitre, 1983 y Melo \& Langebaek, 1996). El lugar, geográficamente hablando, estaba conformado por una pequeña isla contigua a la Ciudad amurallada. El puente de la Media luna (actual puente Heredia) era el único paso que conectaba a Getsemaní con el resto de la ciudad colonial y, a su vez, a ésta última 
“¡Hey! Un patacón ahí” Movilización de significados y construcción de identidades del barrio Getsemaní en Bizarre Foods

Julio Morales Fonseca

con el interior del continente. Con el tiempo, el arrabal adquirió importancia estratégica para la defensa de la Ciudad amurallada, por lo que se empezó a fortificar su periferia. Así nacieron las murallas que hoy en día bordean la avenidilla del Pedregal y que otrora bordearon la calle del Arsenal. La mayor parte de dichas murallas fueron derrumbadas intencionalmente para promover el ensanchamiento del barrio y como método de adquirir elementos para la construcción de viviendas y estructuras. Actualmente sólo sobrevive la muralla que bordea la avenida del Pedregal y algunos baluartes sobre ella.

A partir de la época republicana, Getsemaní siguió considerándose un barrio "periférico", cayendo en el letargo y olvido estatal. Si bien la inauguración del Mercado público de la ciudad, erigido en la bahía de la calle del Arsenal en 1904, impulsó su economía e importancia estratégica, no fue completamente beneficioso para el sector. Este hecho trajo algunas desventajas como falta de higiene en las calles aledañas, aglomeraciones urbanas insalubres, contrabando, prostitución, entre otros. Dichos elementos siguieron impactando en la vida social y en la conciencia colectiva de los habitantes de la ciudad, incluso después del traslado del Mercado público a su ubicación actual (en el sector de Bazurto) a finales de los años 70.

Desde entonces, la importancia de Getsemaní se vino a pique. Tanto así que su fama en la ciudad pasó a ser peyorativa y de marginalidad, destacándose por ser una especie de "zona de tolerancia", donde había expendio de drogas y actividades de prostitución desde los años 80 hasta principios de los 2000. No obstante, a partir de la década del 2000, y en concordancia con la gran apertura económica neoliberal del resto del país, Getsemaní experimentó un nuevo apogeo y transformación en su vida económica, especialmente en relación a la hostelería, similar a la ocurrida en el Centro histórico de Cartagena. No obstante, la esencia nativa del barrio, su accesibilidad económica, su estilo no elitista, tolerante e inclusivo, empieza a diferenciarlo del Centro histórico amurallado. Esto también atrae a la gente local de Cartagena que fue excluida de los espacios públicos y comerciales de la ciudad amurallada debido a sus altos costos. Estos elementos le brindan a Getsemaní un aura de autenticidad, lo que permite atraer a un turismo diverso pero especializado, generalmente joven y ejemplificado en los llamados mochileros (Posso Jiménez, 2013).

Actualmente, el lugar se perfila como un modelo de barrio "moderno", "cool", "bohemio" y de turismo sostenible (Forbes Staff, 2020). Sin embargo, estas últimas y aceleradas transformaciones están impulsando al barrio a sufrir un proceso de gentrificación sin precedentes, parecido al que sufrió el Centro histórico de Cartagena durante los años 90 (Agencia Efe, 2020; Semana, Redacción Arcadia Bogotá, 2013 y Barragán, 2017). Este panorama resulta sumamente preocupante para los habitantes locales y tradicionales del barrio, que se ven afectados por los procesos comunes de la gentrificación; alza de precios de servicios públicos, aumento del impuesto predial, supuesta valorización de predios que conlleva a altos impuestos sobre la vivienda pero que no trae beneficios inmediatos para los propietarios; alzas en el precio de los arriendos que dificulta la instauración de nuevos negocios y viviendas, entre otros. Este fenómeno genera problemas sociales de diversa índole, por ejemplo: 1) de desplazamiento de la población 
“¡Hey! Un patacón ahí” Movilización de significados y construcción de identidades del barrio Getsemaní en Bizarre Foods

Julio Morales Fonseca

autóctona y tradicional del barrio a otros sectores generalmente más deprimidos de la ciudad, 2) de índole moral y cívica al no reconocerse ni respetarse los derechos fundamentales de las personas que habitan en él y 3) la pérdida de la esencia cultural y patrimonial de uno de los barrios más tradicionales de la ciudad.

\section{Metodología}

Para la descripción e interpretación de los datos tenemos en cuenta, por un lado, la etnografía virtual como metodología, considerando que internet es "un contexto abierto para las interacciones sociales donde las prácticas, significados e identidades se entremezclan" (Domínguez et al. 2007, p. 2). La web puede verse como expresiones singulares de la cultura y como repositorio de datos acerca de los modos de proceder y de pensar de los grupos sociales traspasando fronteras étnicas y nacionales (Pauwels, 2012). Por otra parte, acudimos a conceptos relacionados con el lenguaje y la globalización para explicar la construcción de identidades (Blommaert, 2010; Pietikäinen, 2018; Menezes de Souza, 2019; y Stroud, 2017).

A partir de este marco, describimos e interpretamos las relaciones constituidas entre el chef y el resto de los participantes sociales del sub apartado a manera de una narrativa social, es decir, un suceso conformado por participantes, lugares, eventos y desenlaces sociales. Es así como esas relaciones se ven permeadas por varios elementos que las definen, entre ellos el contexto local y su paisaje lingüístico (Lozano, Jiménez-Caicedo \& Abraham, 2020), las significaciones propuestas por el chef a través de su lenguaje (oral, corporal, etc.), los metadiscursos del chef y del programa Bizarre Foods, los usos del lenguaje por parte de los "locales" para comunicar algo al chef y la interpretación que éste les da (o que recibe de sus intérpretes). Este diverso repertorio de recursos semióticos establece distintos elementos identitarios locales, relaciones sociales desiguales de poder y la perpetuación y legitimización de fenómenos sociales adversos para la población local, tales como discursos colonialistas y procesos de gentrificación. Si bien los hechos analizados ocurren en torno al barrio Getsemaní, los procesos epistemológicos descritos, la significación histórica, importancia cultural y preponderancia social que este emblemático barrio aporta a Cartagena hacen que las consecuencias sociales se trasladen al resto de la ciudad y la región Caribe de Colombia.

El análisis se realiza a partir de la observación del video "BIZARRE FOODS Americas Cartagena, COLOMBIA" (Marino, 2014), (42:30 mins. En ese momento disponible en: https://www.youtube.com/watch?v=PsVQKJGtYVQ\&t=1506s\&ab channel $=$ BIZARREFOODS), centrándonos únicamente en el sub-apartado ocurrido en el barrio Getsemaní, el cual transcurre entre el minuto 16:25 y el 19:52.

Para efectos de la descripción e interpretación del video, tenemos en cuenta algunas de las fases analíticas propuestas por Pauwels (2012) para revelar los significados potenciales que ofrecen los recursos multimodales de expresión cultural en la web. Estas fases se refieren a explorar los rasgos y tópicos aparecidos en el video e interpretar, primero, las diferentes 
“¡Hey! Un patacón ahí” Movilización de significados y construcción de identidades del barrio Getsemaní en Bizarre Foods

Julio Morales Fonseca

modalidades presentes en ellos junto a un análisis "negativo" (rasgos o tópicos no explícitos) y, segundo, los puntos de vista y las audiencias implicadas. Combinaremos este análisis con la sociolingüística etnográfica (Heller, Pietikäinen \& Pujoar, 2018) teniendo en cuenta, además, mi propio conocimiento etnográfico del contexto social. Este se sustenta en mi experiencia de primera mano a raíz de las múltiples visitas realizadas a dicho barrio, en especial a la plaza de la Trinidad que es donde ocurre la mayor parte de la acción, y porque soy oriundo de la ciudad de Cartagena.

\section{Resultados}

1) El chef empieza su recorrido por el barrio de Getsemaní (min. 16:30) definiéndolo como el "upstart little brother"3 del Centro histórico de Cartagena, el cual considera como el "destino turístico clásico de Cartagena". Dicha expresión denota que el lugar es o ha sido considerado inferior al Centro histórico, es decir, al lugar "tradicional" de turismo en la ciudad. Esto le otorga una condición inusual, rara, heterodoxa, excéntrica, al barrio de Getsemaní. Las razones para realizar este juicio de valor no son claras, siendo la diferencia más notable entre el Centro histórico y Getsemaní la situación socioeconómica que los separa; el primero es un barrio de lujo y el segundo un barrio tradicional, convertido ahora en bohemio, cultural, de ocio barato, entre otros.

2) Otra definición inicial del barrio dada por el chef es "ecléctico" (min. 16:38) y señala que es hogar de "jóvenes y artistas" incluido su acompañante, Nelson Rainbow ${ }^{4}$. Sin embargo, es este último quién le informa al chef que el barrio es hogar de múltiples familias autóctonas de la ciudad que llevan viviendo en él desde hace "cinco o seis generaciones" (min. 16:49). Luego, el chef narra que "menos de una década atrás, (Getsemaní) era uno de los barrios más duros (toughest) de la ciudad, con presencia de drogas y pandillas urbanas" (min 16:55). Aunado a esto, Rainbow, al hablarle al chef (en inglés) acerca de Getsemaní, pronuncia la palabra barrio en español, en vez de utilizar su traducción inglesa neighborhood u otra similar. Esto lo hace con la intención de darle una caracterización más "callejera", urbana y forajida al lugar donde se encuentran, similar a la jerga utilizada por las pandillas callejeras conformadas por latinos en Estados Unidos.

3) En el minuto 16:58 el chef asegura que, gracias al aumento de la vigilancia policial y programas del gobierno, las personas pueden "caminar de noche con libertad y experimentar la hospitalidad colombiana".

4) En el minuto 17:08 ocurre uno de los eventos más interesantes del sub apartado en Getsemaní; el chef y sus acompañantes (camarógrafo incluido) son invitados, espontáneamente, por una

\footnotetext{
${ }^{3}$ Expresión cotidiana del inglés que vendría a significar como "alguien venido a más" o "algo que ha surgido desde abajo con rapidez" o "alguien que se da más importancia de la real".

${ }^{4}$ Nelson Rainbow se presenta como un periodista británico afincado en Cartagena y oficia como guía e intérprete del chef Zimmern durante su visita a Getsemaní. Cabe anotar que durante el episodio entero el chef se hace acompañar de varios guías o intérpretes locales (oriundos de la región), siendo el señor Rainbow es el único extranjero.
} 
“¡Hey! Un patacón ahí” Movilización de significados y construcción de identidades del barrio Getsemaní en Bizarre Foods

Julio Morales Fonseca

parroquiana a entrar y conocer su casa y familia; según informan al chef, se trata de una casa colonial del siglo XVIII habitada por cuatro generaciones de la misma familia. El chef describe el evento como un "signo catártico y desafiante", por parte de la familia que lo invita, de reapropiarse del barrio, luego de "décadas de necesitar mantener cerradas las puertas de su casa" (min. 17:21). La mujer que lo invitó le habla en inglés y le dice que "tiene dos casas en Cartagena donde puede quedarse (señala sus dos casas propias) cuando quiera regresar".

5) En el minuto 17:47, el chef asegura que los residentes de Getsemaní están reclamando su barrio de "otras formas emocionantes". Su acompañante, Rainbow, le comenta que el barrio "es un lugar donde la gente viene a ver TV, a comer y a beber".

6) El chef describe la plaza de la Trinidad como "la más antigua de Cartagena" (min. 17:58). Dice que hoy en día es un "espacio social" para las familias locales, completado con su manera única de presentar comidas callejeras nocturnas. Al acercarse a un puesto de comida callejera, el chef ordena un "Patacón con todo" (pronunciándolo en español). El chef describe esta comida como "plátano fresco a la plancha con, literalmente, toda la comida basura (junk) que puedan ponerle encima". Rainbow le informa que cuesta siete mil pesos (dos dólares estadounidenses aproximadamente en 2015), queriendo notar lo barato que es, a lo cual el chef exclama "increíble". Al serle entregado el plato de comida, lo primero que el chef nota es su peso: "pesa unas tres libras". Señala que el plato normalmente podría alimentar a una familia de cinco personas y que su intención de probarlo ha atraído a una gran multitud (efectivamente, un numeroso grupo de gente se ha congregado para verlo comer). Sus primeros comentarios luego de probar la comida es que "sintió que hubiera comido siete arepas", que es adictivo, que es todo "sal, sal y grasa" (a lo que Rainbow dice que es el "sueño americano") y finaliza diciendo que es "la heroína del gremio culinario" (min. 19:07). Pregunta si a los niños locales les gusta ese tipo de comida, a lo cual entra en escena el hijo de Rainbow para probar el plato. El chef llama al niño un connoiseur de la comida callejera local. El niño prueba la comida y dice que está deliciosa. De manera un poco irónica, a mi parecer, el chef le pregunta al niño "si él cree que los niños de todo el mundo deberían venir a Cartagena a probar esto” (min. 19:26), a lo cual el niño le responde que sí.

7) A manera de conclusión sobre el subapartado de Getsemaní (min. 19:40), el chef narra que "para bien o para mal, sabores como éste (Patacón con todo) se están convirtiendo en parte del paisaje de la histórica Cartagena" y que para probar "sabores más auténticos de Colombia, se debe dejar la ciudad atrás". 
“¡Hey! Un patacón ahí” Movilización de significados y construcción de identidades del barrio Getsemaní en Bizarre Foods

Julio Morales Fonseca

\section{Discusión}

El multilingüismo estratégico se refiere al modo como la gente modifica, presenta o reconfigura el lenguaje en sus contextos locales, utilizando su repertorio lingüístico, basado en jerarquías lingüísticas, para lograr sus cometidos (Pietikäinen, 2018). Es decir, la manera en la que la gente toma ventaja de sus habilidades y conocimientos multilingües (sean del nivel que sean) para hacer más efectiva la comunicación con otros potenciales actores; de este modo, es posible brindar recursos y capitales que podrían no ser accesibles mediante el uso del lenguaje local tradicional. El multilingüismo estratégico implica la "inclusión temporal de algunas lenguas y exclusión de otras, así como el establecimiento de límites claros que prometen la redistribución de autoridad y recursos" (Pietikäinen, 2018, p. 188). Esta inclusión de lenguas no sólo se limita a recursos semánticos, sino también con elementos identitarios autóctonos, como símbolos o representaciones. En nuestro caso, la mayoría de puestos de comidas callejeras de la plaza de la Trinidad tienen alguna decoración relativa a Cartagena o al Caribe colombiano: murallas de Cartagena, palmeras, cocos, o a símbolos nacionales propios de la región Caribe como el sombrero vueltiao ${ }^{5}$. Estos símbolos identitarios cumplen una doble función: 1) son reconocidos por los turistas extranjeros que buscan reivindicar la idea de estar consumiendo y visitando un sitio "exótico" y autóctono y 2) perpetúan y (re)presentan nociones de exoticidad que conforman la identidad cartagenera y nacional.

De igual modo, los nombres de las comidas, de los restaurantes aledaños y la forma de los locales de presentar estos elementos responden a la intención de dirigirse a un público extranjero, al estar traducidos completa o parcialmente al inglés. Así, por ejemplo, el menú de la venta estacionaria visitada por el chef anuncia sus nombres del siguiente modo: patacón con todo (patacón with everything), hamburguesa doble carne (double meat hamburger), perro salvaje (Wild $d o g$ ), choriperro (choriperro), perro sencillo (Simple dog). En Cartagena se acostumbra a llamar al perro caliente simplemente "perro"; probablemente, los vendedores asumen que en inglés ocurre lo mismo, por lo que el hot dog pasa a llamarse simplemente "dog". En otro caso, el Choriperro ${ }^{6}$ no tiene traducción literal, por lo que mantiene su nombre en español; del mismo modo, la palabra patacón no cuenta con una traducción en Google translator, por ejemplo, por lo que el plato se traduce parcialmente.

Dirigirse a turistas para atraerlos es parte de la estrategia del multilingüismo estacional. Señala Pietikäinen (2018) que los "sitios de multilingüismo estacional se caracterizan por cambios económicos y de movilidad (...) en donde nuevos requerimientos de lenguaje son necesarios para abarcar los nuevos flujos turísticos" (p.186). Así mismo, los cambios socioeconómicos, la movilidad y las nuevas estructuras económicas contemporáneas, abren nuevos valores sociales que exigen no solo desarrollar habilidades multilingües sino también habilidades de mercado para

\footnotetext{
${ }^{5}$ Sombrero de fabricación artesanal y de raíces indígenas Zenú que en los últimos años se ha convertido en icono cultural identitario de Colombia.

${ }^{6}$ Perro caliente hecho con chorizo.
} 
“¡Hey! Un patacón ahí” Movilización de significados y construcción de identidades del barrio Getsemaní en Bizarre Foods

Julio Morales Fonseca

las lenguas autóctonas, que pasan a ser índices de autenticidad y diferenciación (Pietikäinen, 2018). Así, algunos sitios alrededor de la plaza de la Trinidad adoptan nombres "autóctonos" o de la jerga local como método para imprimir originalidad, autenticidad y distinción a su negocio. Encontramos, por ejemplo, el restaurante Coroncoro ${ }^{7}$, Malagana ${ }^{8}$ Bar, Cabildo ${ }^{9}$ Gastromar, María Palenque $^{10}$, El Bololó ${ }^{11}$ : bowls del caribe, Gelatería Ceiba ${ }^{12}$, entre otros.

Según Menezes de Souza (2019), citando a Boaventura de Santos (2010), los Globalismos localizados son "imposiciones, en lugares particulares, de elementos que se originan en la transnacionalidad hegemónica 'global'” (p. 19). Dada su fuerza hegemónica, tales elementos no pueden resistirse fácilmente, pero pueden "recontextualizarse para adaptarse a las condiciones e intereses locales" (Menezes de Souza, 2019, p.19). Esto puede verse en el ejemplo de los perros calientes que, generalmente y en su presentación moderna, son considerados como una invención estadounidense $^{13}$. Sin embargo, en la plaza de la Trinidad, son "recontextualizados" para que respondan a los intereses de la gente local: sus nombres se adecuan al idioma y, en especial, a los modismos y jergas locales. También sucede con los restaurantes de alrededor de la plaza, donde las comidas y cócteles llevan nombres producto de una mezcla de elementos hegemónicos globales y locales (Martini caribeño, Cuba libre cartagenero, Mula enamorada y Mula brincona (a base de Vodka), pizza tablua ${ }^{14}$, entre otros). La preparación se hace casi estrictamente con ingredientes locales, que distingue a las comidas como más autóctonas, y lo que a su vez podría considerarse como un elemento adicional a la construcción de estos globalismos localizados. Esto puede ser visto como una forma de lenguaje.

Por otra parte, Menezes de Souza \& Guilherme, citando a Khubchandani (1997), se refieren a los Repertorios verbales; los definen como un proceso dinámico de interacción lingüística, en donde elementos universales y únicos se apiñan en un determinado contexto. Según Khubchandani,

Lo que se percibe como lo global y lo local cambiará dinámicamente según cada contexto de interacción verbal (...) lo que se considere universal (global/sistemático) o único (local/contingente) dependerá de la relación que uno tenga con el

\footnotetext{
${ }^{7}$ Tipo de pescado muy popular que, además, es el nombre de una canción popular o folclórica muy famosa en el Caribe colombiano.

${ }^{8}$ Municipio al sur de Cartagena de población predominantemente afrocolombiana. Al igual que San Basilio de Palenque, Malagana fue fundado por esclavos negros cimarrones durante la época de la colonia.

${ }^{9}$ Organización administrativa utilizada por los españoles durante la época colonial para agrupar a los pueblos y territorios indígenas bajo su poder.

${ }^{10}$ San Basilio de Palenque es un corregimiento al sur de Cartagena fundado como un palenque por esclavos cimarrones durante la época colonial. Se conoce como la primera población libre de la América colonial y fue declarado Patrimonio cultural e inmaterial de la humanidad en 2005.

${ }^{11}$ Expresión de la jerga cartagenera que denota una situación caótica o desordenada.

12 Árbol común en el Caribe colombiano y que posee connotaciones sagradas para las culturas prehispánicas.

${ }^{13}$ Aunque, 'hot dog' es una recontextualización de la voz alemana 'dachshund'

${ }^{14}$ Palabra de la jerga local cartagenera que denota algo grande o inmenso.
} 
“¡Hey! Un patacón ahí” Movilización de significados y construcción de identidades del barrio Getsemaní en Bizarre Foods

Julio Morales Fonseca

interlocutor, el motivo de la interacción y los recursos lingüísticos disponibles para cada uno. (Menezes de Souza \& Guilherme, 2019, p. 229)

Así, la relación entre los distintos repertorios verbales de un sujeto dependerá del tipo de relación que se establezca con él, ya sea comercial, amistosa, romántica, etc. En nuestro episodio de Bizarre Foods, los participantes sociales locales reaccionan y se comunican de acuerdo a la situación y relación que lleven con el chef: de modo amistoso (vendedores), de guía o pedagógica (Rainbow) o incluso afectiva (mujer que lo invita a su casa). Los actores sociales utilizan un repertorio verbal dinámico adaptado a esta relación y encaminado a cumplir sus objetivos. Este tipo de interacciones con foráneos configura el llamado ethos de la comunicación como concepto que guía el discurso de una comunidad. Esto hace parte de la ética de Khubchandani (2018) en relación a los lenguajes glocales (Guilherme, 2018 y Menezes de Souza \& Guilherme, 2019) y propicia la aparición del ethos plurilingüístico local propuesto por el autor que conformaría una “epistemología glocal” como método de resistencia ante las epistemologías lingüísticas impuestas por el "Norte global".

Los procesos postraciales tales como pérdida de identidad, de historias, de lugares, etc., descritos por Christopher Stroud (2017) en su investigación en la Old Biscuit Mill (OBM), en Sudáfrica, se acercan mucho a lo acontecido en el contexto de las comidas callejeras de Getsemaní en Cartagena. Así, el hecho de que ciertos 'tipos de cuerpos' sean privilegiados sobre otros es un factor clave a investigar en Getsemaní. Según lo señalado por Stroud, el chef hace una cuidadosa construcción de realidades postraciales: las que están escritas por los privilegiados, que resultan ser blancos con "lenguas del norte". Este proceso recuerda las "estructuras de sentimientos" de Raymond Williams (1987) que son, según dice el autor:

Modos de responder a un mundo particular que en la práctica no es experimentado como un modo alternativo a otros, sino que es experimentado como el único modo posible. Sus medios, sus elementos, nos son proposiciones o técnicas; son sentimientos relacionados que se materializan. De la misma manera, es accesible a otros no a través de la argumentación lógica o las destrezas profesionales, por sí solos, sino por experiencia directa -una forma y un sentido, un sentimiento y un ritmo - en la obra de arte, la obra de teatro como un todo. (Williams, 1987, p.18)

Por ejemplo, los bares y restaurantes que circundan la plaza son demasiado caros para los lugareños. Por otro lado, los puestos de comidas callejeras mantienen los precios accesibles para la gente local del barrio y la ciudad. Sin embargo, los "turistas blancos privilegiados" siguen teniendo acceso a las comidas callejeras e incluso en las proximidades y en los hostales cercanos se venden toures turísticos de "nocturnal life" o "enjoy as a local" que consisten, entre otras cosas, en comer de las comidas callejeras de la plaza de la Trinidad para "experimentar la vida local". Así, lo denominado "vida local" es colonizado y presentado como un discurso que da a entender que lo "local" está presente en las comidas callejeras pero no en los restaurantes aledaños. De esta 
“¡Hey! Un patacón ahí” Movilización de significados y construcción de identidades del barrio Getsemaní en Bizarre Foods

Julio Morales Fonseca

manera, se traza una jerarquía dominante y acaparadora por parte de los turistas foráneos, al pretender acceder a mercados que no están original o exclusivamente diseñados para ellos. De esta manera, las significaciones sociales en torno a la identidad, lo auténtico, exótico y, en suma, la otredad, del barrio Getsemaní se (re)producen en producciones como Bizarre Foods, donde el chef se acerca a comer en sus puestos callejeros, no en sus restaurantes. Esto implica que la idea de localidad, representada en las comidas callejeras de la plaza, no sólo es válida y funcional sino que está lo suficientemente popularizada como para que el chef y su equipo de trabajo la hayan perseguido y, ahora, perpetuado.

Pavlenko (2006) señala que diversos estudios en lingüística y psicoanálisis han demostrado que el lenguaje puede "crear mundos diferentes" para los hablantes de varias lenguas, ya que pueden llegar a sentir un cambio en su percepción del Yo al hablar. Esto sucede, mayoritariamente, en ambientes de multilingüismo donde varias lenguas son utilizadas en la vida común. Esta percepción de cambio del Yo, al utilizar un lenguaje específico en un contexto determinado, puede llevar a las personas bilingües biculturales a tener un comportamiento verbal diferente al ordinario, hecho que puede ser notado por sus interlocutores u observadores. Un gran abanico de elementos inconscientes como significaciones, prejuicios, repertorios lingüísticos, conflictos internos, imaginarios individuales y colectivos, etc., pueden ser exhibidos en un lenguaje y en el otro no (Pavlenko, 2006).

En el caso de los actores sociales presentes en el recorrido del chef por Getsemaní, se evidencia un cambio de actitud inclinado hacia la condescendencia, el servilismo, "querer agradar al otro", entre otros tipos de estrategias que buscan despertar la empatía del chef y su grupo. Por ejemplo, en la escena número cuatro (4), en el minuto 17:08, el chef y su acompañante son invitados a pasar a una casa cercana a la plaza de la Trinidad. Según el chef, esto sucedió luego de que fue "pillado husmeando a través de la ventana". En el interior, una mujer cartagenera, que habla con el chef en inglés, se identifica como integrante de una familia que lleva cuatro generaciones habitando esa casa y lo invita a conocer su casa y a su familia. Según la narración del chef, "hay comida frita fresca" (lo que supone la idea de que lo invitaron a comer). Sólo la mujer que invita al chef participa de la conversación (o al menos eso deja ver las imágenes grabadas). Por otro lado, el chef alaba repetidamente la belleza de la casa y menciona lo "honrado" que se encuentra por ser invitado a ella. Su gestualidad denota solemnidad. Cuando la mujer se dirige al chef, ambos actores adoptan una postura de diversión (con sonrisas ligeramente burlonas en sus rostros) y de gratitud. El chef señala que "luego de décadas de tener que mantener las puertas cerradas, este recibimiento cálido de vecindad cordial es una señal catártica e incluso desafiante de que su barrio es realmente suyo de nuevo". Al final, el chef abraza y besa a la mujer en la mejilla luego de que esta lo invita a volver a visitarla en el futuro.

Sobre este momento, varias cosas pueden resaltarse. En primer lugar, el chef refuerza la noción de que el barrio de Getsemaní era, en el pasado, un lugar donde las puertas se mantenían cerradas debido a la inseguridad. Ante esto, se entiende que, en el pasado, la gente de Getsemaní no era hospitalaria ni cordial con los transeúntes por miedo a ser asaltados o violentados de otra 
“¡Hey! Un patacón ahí” Movilización de significados y construcción de identidades del barrio Getsemaní en Bizarre Foods

Julio Morales Fonseca

manera. Sin embargo, numerosos testimonios de habitantes locales y fotografías antiguas demuestran que la gente permanecía con las puertas abiertas y transitando con normalidad por la calle.

A su vez, el chef no repara en la posición estereotipada privilegiada que él (re)presenta: blanco, evidentemente extranjero (por su modo de vestir y hablar, por ejemplo), acompañado de otro sujeto igual a él en ese aspecto y, más importante aún, acompañados de un camarógrafo (que no sabemos si era extranjero o local). Estos elementos le imprimen una serie de características que denotan privilegios y lo hacen resaltar por encima del resto de transeúntes del sector. Es así como, por ejemplo, resulta difícil pensar que la mujer que invita al chef a entrar y conocer la belleza de su casa del siglo XVIII, haga lo mismo con un habitante local, de otro sector de la ciudad, un turista nacional o incluso un turista extranjero de los llamados mochileros, o simplemente con alguien que no esté acompañado de un camarógrafo. Por lo menos a mí, que paso regularmente por aquella calle, nunca me ha sucedido, ni a nadie que yo conozca.

Por otro lado, el chef declara que el hecho de haber sido invitado a la casa de la señora cartagenera es símbolo de que el barrio pertenece a los getsemanicences de nuevo. Esta posición denota un pensamiento jerárquico colonialista ya que el chef, nuevamente desconociendo que habla desde un lugar de enunciación privilegiado, asume que la apropiación cultural e identitaria de un barrio por parte de sus propios habitantes es posible gracias al hecho de que visitantes como él puedan entrar en sus casas y conocerlas o conocer el barrio. Esto lleva a pensar que el barrio de Getsemaní era "inexistente" antes de la llegada del chef o de visitantes de su misma condición simbólica y social. De esta manera, se refuerza el estereotipo o noción cultural de que los lugares exóticos son descubiertos una vez que el occidente civilizado, encarnado en la figura del chef, llega a ellos. Se desconoce, así, la historia, procesos de habitación, flujos migratorios, identidades culturales y tradiciones autóctonas que, evidentemente, existían, existen y existirán en el barrio, indiferentemente de la llegada de turistas norteamericanos como el chef.

Finalmente, al centrarnos en el lenguaje corporal de los actores sociales involucrados, observamos posturas condescendientes, tonos de voz amables e incluso coquetos (como el de la mujer cartagenera con el chef). La grabación muestra únicamente los ofrecimientos y hospitalidades por parte de la familia cartagenera, pero nunca muestra que el chef o su acompañante den una explicación sobre ellos mismos o la labor que realizan, dando a entender que no es importante (o que es natural que no lo haga) que una persona extranjera se presente y explique quién es y por qué está ahí. Al final, cuando el chef se despide, lo hace abrazando y dándole un beso en la mejilla a la mujer que lo invitó. Este comportamiento puede parecer atrevido o respetuosamente inapropiado para una persona que acaba de conocer a otra, especialmente en el contexto de las normas sociales cartageneras y es un ejemplo del lenguaje modificado, inconscientemente, en contextos de multilingüismo, tal y como lo señala Pavlenko (Cabe preguntarse si todo este evento social (invitar a un desconocido a una casa ajena) hubiera sucedido de manera similar si un transeúnte "latino" hubiese visitado las calles del centro turístico de alguna ciudad estadounidense. 
“¡Hey! Un patacón ahí” Movilización de significados y construcción de identidades del barrio Getsemaní en Bizarre Foods

Julio Morales Fonseca

Durante su visita, el chef hace algunos comentarios que podrían catalogarse como retrógrados y prejuiciosos, alineados a las perspectivas hegemónicas del Norte global. Por ejemplo, en la escena tres (3) menciona que, gracias a la vigilancia policial, Getsemaní es ahora un lugar seguro. Efectivamente, si algo denota una alta presencia policial en algún lugar es que no es seguro. La idea de que la vigilancia policial es sinónimo de seguridad hace parte de las ideologías neoliberales y de derecha que acarrean nociones generalmente perjudiciales para las comunidades más vulnerables, como es el caso de Getsemaní, donde se propicia la aparición de fenómenos adversos como la gentrificación.

Sin embargo, el ejemplo más claro de la (im)posición ideológica del chef ocurre durante la escena número seis (6) cuando, después de probar el Patacón con todo, el chef lo describe como "la heroína del gremio culinario" (min. 19:07); se sugiere la asociación de ideas entre una comida callejera y una droga universalmente conocida con relación al lugar donde se encuentran: Colombia, una nación productora de drogas. La expresión del chef denota un desconocimiento total del contexto, así como una tendencia prejuiciosa a encasillar la realidad, (de)formándola para que encaje en el ya desueto sistema discriminatorio que el mundo exterior tiene sobre Colombia.

\section{Conclusiones}

Bizarre foods evidencia algunos modelos epistemológicos colonialistas extranjeros que histórica e ideológicamente han sido implantados en el entorno local de Cartagena. Estos hacen parte de una estrategia global, hegemónica y jerarquizada que produce y reproduce ideas anacrónicas, discriminantes y prejuiciosas sobre lugares del Sur global. Según estas perspectivas del Norte, todo lo del Sur global está atravesado por lo exótico, la inseguridad, la pobreza, las drogas, etc. Estos elementos se recontextualizan a través de los repertorios lingüísticos exhibidos por el chef para romantizar, exotizar, reproducir y fetichizar. La manera en la que el lenguaje local se modifica, presenta, altera y reconfigura responde a esta jerarquización.

En Bizarre Foods vemos cómo el lugar de enunciación de los hablantes se constituye a través de sus relaciones sociales (comprar, vender, conversar) y cómo este lugar les otorga su subjetividad. Por ejemplo, la noción de "experiementar la vida local", si bien es explotada por los dueños de hostales, vendedores de planes turísticos y, de manera indirecta, vendedores de comidas callejeras de la plaza de la Trinidad, termina construyéndose a partir de una remanente idea colonialista de los visitantes que ven esta vida local íntimamente relacionada con las comidas callejeras y desean apropiársela. Dado que son actos de cultura, esos modos de proceder se pueden codificar mediante textos de distinto orden que transmiten significados; éstos deben descifrarse o negociarse, y no solo a nivel intercultural, sino también, a menudo, intra-culturalmente, con el fin de llegar a acuerdos que favorezcan la comunicación o, por lo menos, la hagan posible. De esta manera, los actores sociales utilizan un repertorio verbal dinámico adaptado.

La identidad local -lo auténtico y diferenciado- se ve permeada y definida por los flujos epistemológicos tanto de repertorios lingüísticos como de capitales simbólicos y sociales. Así, los 
“¡Hey! Un patacón ahí” Movilización de significados y construcción de identidades del barrio Getsemaní en Bizarre Foods

Julio Morales Fonseca

lenguajes glocales conforman fenómenos complejos que involucran resistencias contrahegemónicas a los lenguajes hegemónicos globalizados; lo local y lo global pueden existir e interrelacionarse en el nivel de región o de nación. En el caso de Bizarre Foods se aportan nuevos elementos globales al contexto de la plaza de la Trinidad y, a su vez, se exportan elementos locales de Getsemaní y Cartagena al "Norte global" (como parte del público al cual está dirigido el programa): sus comidas, su repertorio verbal, su ethos plurilingüístico, entre otros, pasan a ser parte del repertorio cultural de lo global. Se trata, pues, de un intercambio epistémico, no obstante, desigual e inequitativo, ya que lo que llega como "global", traído por el chef, viene con una esencia hegemónica de superioridad jerárquica, producto de las significaciones privilegiadas que arraigan su origen en el Norte global. Por otro lado, lo local que se lleva el chef y el programa Bizarre Foods, llega al Norte global arrastrando, a su vez, las desventajas, estereotipos y significaciones propias del Sur global, (pobreza, exoticidad, atraso cultural, primitivismo, etc.). Esta configuración desigual construye, perpetúa, presenta y representa prejuicios, imágenes alteradas, nociones vagas y superficiales acerca de ambas regiones culturales. Así mismo, afecta, a fin de cuentas, las significaciones y el inconsciente colectivo de las personas que participan de programas como Bizarre Foods, no sólo como consumidores del programa (televidentes del Norte) sino como protagonistas de él (residentes del Sur global).

Los repertorios verbales, los procesos postraciales y las estructuras de sentimientos, junto a cambios en la percepción del Yo, trayendo a flote elementos inconscientes, en contextos de multilingüismo, construyen jerarquías sistémicas y sistemáticas, lo que implica la complicidad de todos los involucrados en la conversación que pueden sentir dichas jerarquías, aunque no las expresen con franqueza. En el análisis, puede descubrirse que ciertos usos del lenguaje utilizados para vender a los locales traigan el sentimiento de "no estar haciéndolo bien" cuando se utiliza con los extranjeros. O viceversa. Para nosotros, estos sentimientos revelan las órdenes de (in)visibilización que los vendedores reciben dentro de las estructuras de poder diseñadas para satisfacer al público (capital) extranjero.

Cabe preguntarnos, como investigadores del sur, ¿qué estamos contando? Y especialmente ¿cómo lo estamos contando? Es posible que al pertenecer al entramado de una academia del Sur no obstante colonizada por las epistemologías del Norte, seamos cómplices de la misma hegemonización epistémica global que intentamos denunciar, perpetúandola mediante investigaciones sesgadas que privilegien la voz de cierto tipo de actores sociales sobre otros. Tal y como Menezes de Souza \& Guilherme (2019) y Heller et al. (2018) sugieren, es necesario que, como investigadores del Sur, realicemos una reflexión de nuestro propio lugar de enunciación en nuestras investigaciones. Desde una perspectiva del sur, lo que se ve en los estudios del lenguaje es que estos no tienen en cuenta las genealogías del lingüista y, entonces, el conocimiento parece universal. El nuevo paradigma investigativo implicaría tener en cuenta también a los sujetos en sus contextos históricos, ideológicos, raciales (racistas), culturales, lingüísticos, y no reducir esto solo a la movilidad. 
“¡Hey! Un patacón ahí” Movilización de significados y construcción de identidades del barrio Getsemaní en Bizarre Foods

Julio Morales Fonseca

\section{Referencias}

Agencia Efe. (2020, enero). La gentrificación amenaza a Getsemaní, uno de los barrios más «cool» del mundo. QUÉPASA. Recuperado de https:/quepasamedia.com/noticias/mundo/sudamerica/la-gentrificacion-amenaza-agetsemani-uno-de-los-barrios-mas-cool-del/

De Anglería, P. (1944). Décadas del nuevo mundo. Buenos Aires: Editorial Bajel.

Barragán, M. (2017, julio). Gentrificación: Fronteras que amplían la desigualdad. DEJUSTICIA. Recuperado de https://www.dejusticia.org/column/gentrificacion-fronteras-que-amplianla-desigualdad/

Bernal, C. \& Orjuela, G. (1992). Prospección arqueológica en el municipio de Turbana, departamento de Bolívar. Boletín de Arqueología. 3(7), 7-79.

Blommaert, J. (2010). The sociolinguistics of globalization. Cambridge: Cambridge University Press.

Domínguez, D., Beaulieu, A., Estalella, A., Gómez Cruz, E., Schnettler, B., Read, R. (2007). Virtual Ethnography. Forum Qualitative Sozialforschung / Forum: Qualitative Social Research, 8(3), 1-5. http://nbn-resolving.de/urn:nbn:de:0114-fqs0703E19

Dussan de Reichel-Dolmatoff, A. (1954). Crespo un nuevo complejo arqueológico en el norte de Colombia. Revista Colombiana de Antropología. 1, 173-178.

Forbes Staff. (2020, enero). Getsemaní, el barrio de Cartagena entre los más 'cool' del mundo. FORBES COLOMBIA. Recuperado de https://forbes.co/2020/01/03/forbes-life/getsemaniel-barrio-de-cartagena-entre-los-mas-cool-del-mundo/

Guilherme, M. (2018). 'Glocal Languages': The 'Globalness' and the 'Localness' in World Languages. In S. Coffey \& U. Wingate (eds.) New Directions for Research in Foreign Language Education. pp. 79-96. New York: Routledge.

Heller, M., Pietikäinen, S., \& Pujoar, J. (2018). Critical sociolinguistic research methods: studying language issues that matter. New York: Routledge.

Kelly, C. (2014). Bizarre Foods: White Privilege and the Neocolonial Palate. Scholarship and Professional Work - Communication. 97, 1-26.

Khubchandani, L. (1988). Language in a Plural Society. Shimla: Indian Institute of Advanced Study.

Khubchandani, L. (1997). Revisualizing Boundaries: A Plurilinguistic Ethos. New Delhi: Sage Publications.

Lemaitre, E. (1983). Historia general de Cartagena, la independencia. Bogotá: Banco de la República.

Lozano, M., Jiménez-Caicedo, J. \& Abraham, L. (2020). Linguistic Landscape projects in language teaching: opportunities for critical language learning beyond the classroom. En Malinowski, D.; H. M. Maxim \& S. Dubreil (Eds.), Language Teaching in the Linguistic Landscape: Mobilizing Pedagogy in Public Space. Heidelberg: Springer, pp. 17-42.

Marino, C. (productor). (2012-2014). Bizarre Foods Americas [serie de televisión]. U.S: Tremendous Entertainment.

Melo, J. y Langebaek, C. (1996). Historia de Colombia: el establecimiento de la dominación española. Bogotá: Presidencia de la República. 
“¡Hey! Un patacón ahí” Movilización de significados y construcción de identidades del barrio Getsemaní en Bizarre Foods

Julio Morales Fonseca

Menezes de Souza, L-M. T. (2019). Glocal languages, Coloniality and Globalization from below. In, M. Guilherme and L-M T. Menezes de Souza (eds). Glocal Languages and Critical Intercultural Awareness. The South Answers back. Pp. 17-41. New York: Routledge.

Menezes de Souza, L-M. T. \& Guilherme, M. (2019). Conclusion: Towards globalization from below. In M. Guilherme and L-M. T. Menezes de Souza (eds). Glocal Languages and Critical Intercultural Awareness. The South Answers back. Pp. 228-241. New York: Routledge.

Pauwels, L. (2012). A multimodal framework for analyzing websites as cultural expressions. Journal of Computer-Mediated Communication, 17, 247-265.

Pavlenko, A. (2006). Bilingual selves. In A. Pavlenko (ed.). Bilingual minds: Emotional experiences, expression, and representation, pp. 1-33. Cambridge: Cambridge U niversity Press.

Pietikäinen, S. (2018). Investing in indigenous multilingualism in the Arctic. Language and Communication, 61 (Part B, September), 184-195. https://doi.org/10.1016/j.langcom.2018.05.001

Pineda, R. (1988). Los Caribes. En Historia de Colombia-La Colombia más Antigua, Bogotá: Enciclopedia Salvar Editores Colombiana S.A.

Posso Jiménez, L. (2013). Getsemaní: de barrio periférico a núcleo de la escena cultural contemporánea. Visitas al patio, 7, 87-104. https://doi.org/10.32997/2027-0585-vol.0-num.7-2013-1691

Redacción Arcadia Bogotá (2013, febrero). La Gentrificación en Cartagena: El desalojo neoliberal. SEMANA. Recuperado de https://www.semana.com/impresa/antropologia/articulo/el-desalojo-neoliberal/31176/

Reichel-Dolmatoff, G. (1955). Excavaciones en los conchales de la Costa de Barlovento. Revista Colombiana de Antropología. 4, 248-272.

Reichel-Dolmatoff, G. (1986). Introducción a la Arqueología de Colombia, un texto introductorio. Bogotá: Fundación Expedición Botánica.

Reichel-Dolmatoff, G. (1990). Sierra Nevada: cambio cultural. Caribe Colombia. Bogotá, Colombia: Financiera Energética Nacional.

Santos, B. de S. (2010). A Non- Occidental West: Learned ignorance and an ecology of knowledges. Theory Culture Society, 26, 103-123.

Schroeder, J. (1998). Consuming Representation: A Visual Approach to Consumer Research. In Barbara B Stern (Ed.). Representing Consumers: Voices, Views and Visions, pp. 193-230. London: Routledge.

Stroud, C. (2017). A postscript on the postracial. In C. Kerfoot and K. Hyltenstam (eds). 'Entangled Discourses: South-North Orders of Visibility', pp. 230-237. New York: Routledge.

Téwodros, W. (2019). Exotica Africana: interrogating African otherness in Bizarre Foods with Andrew Zimmern. Popular Communication: The International Journal of Media and Culture. Recuperado de:

https://doi.org/10.1080/15405702.2019.1637524.

Williams, R. (1987). Drama from Ibsen to Brecht. London: The Hogarth Press. 